\title{
Vivienda, cambio poblacional y desplazamiento en un barrio en proceso de gentrificación. El caso de Sant Antoni (Barcelona)
}

Antonio López-Gay. Universitat Autònoma de Barcelona, Barcelona, España.
Anna Ortiz-Guitart. Universitat Autònoma de Barcelona, Barcelona, España.
Miguel Solana-Solana. Universitat Autònoma de Barcelona, Barcelona, España.

RESUMEN | Las condiciones de acceso a la vivienda en las grandes ciudades españolas han empeorado desde 2015, sobre todo como consecuencia de un fuerte aumento del precio de la vivienda. Esta tendencia se ha manifestado con especial intensidad en espacios de elevada centralidad, pero que habían permanecido ajenos a episodios previos de transformación urbana y sociodemográfica. En este artículo, nos aproximamos al reciente proceso de gentrificación del barrio de Sant Antoni de Barcelona a través de una metodología de análisis mixta, que combina lo cualitativo y lo cuantitativo. Esta aproximación nos permite diseccionar los mecanismos de sustitución sociodemográfica de la población, subrayando el papel protagonista del mercado de la vivienda. Sant Antoni es un caso relevante, ya que en él se manifiestan dinámicas emergentes poco estudiadas, como la turistización o la inmigración internacional cualificada, aspectos que son cada vez más necesarios de incorporar para entender los procesos de gentrificación en el sur de Europa.

PALABRAS CLAVE | gentrificación, geografía urbana, transformaciones socioterritoriales.

ABSTRACT | The conditions of access to housing in large Spanish cities have worsened since 2015, mainly because of a dramatic increase in housing prices. This trend has significantly affected high centrality areas that had remained unaltered to previous urban and sociodemographic transformation episodes. In this article, we approach the current gentrification process of Sant Antoni, a neighborhood in Barcelona, through a mixed methodology, combining qualitative and quantitative analysis. This approach allows us to dissect the mechanisms of neighborhood change underlining the housing market's leading role. Sant Antoni is a relevant case because largely unexplored emerging dynamics are taking place in the neighborhood, such as tourism or qualified international migration, elements that are increasingly necessary to understand gentrification processes in southern Europe.

KEYWORDs | gentrification, urban geography, socio-territorial transformations. 


\section{Introducción y justificación}

La vivienda y su relación con la población es uno de los temas protagonistas de las políticas públicas actuales en España. Preocupa, en especial, el difícil acceso a la vivienda, el aumento de los precios, la escasa construcción de vivienda social y los desahucios. Para entender el panorama actual español en materia de vivienda es fundamental retroceder en el tiempo. El crecimiento económico durante el cambio de siglo tuvo en la construcción y en el empuje del mercado inmobiliario uno de sus pilares fundamentales. Según datos del Ministerio de Fomento (2020), el valor tasado medio de vivienda libre en Espańa se multiplicó por tres entre 1995 y 2007. La crisis de 2008, con su carácter financiero pero a la vez inmobiliario, tuvo un fuerte efecto sobre las economías de los países que habían basado gran parte de su crecimiento económico en la inversión en vivienda, como es el caso de Estados Unidos o de países europeos como Irlanda, Islandia y España. En España, el valor tasado medio de la vivienda libre se desplomó un 31\% entre 2008 y 2014 . A partir de ese momento se extendió la alarma social debido al incremento constante del número de desahucios por impago de las hipotecas, que se habían concedido en los años del boom económico (Cano \& Etxezarreta, 2014).

Actualmente, los problemas de acceso a la vivienda y la inseguridad residencial están entre las principales preocupaciones para la sociedad española (Módenes, 2019), especialmente en las grandes ciudades, ya que los precios, sobre todo de alquiler, han experimentado un crecimiento continuo desde 2014. Barcelona, junto con Madrid, son los casos paradigmáticos de este cambio de ciclo en los precios, que, según el Banco de Espańa, se han incrementado alrededor de un 50\% en el mercado de alquiler durante el quinquenio 2014-2019 (López-Rodríguez \& de los Llanos Matea, 2019). Este aumento ha obligado a la población arrendataria a destinar una proporción creciente de sus ingresos al pago de la vivienda (Observatori Metropolità de l'Habitatge de Barcelona, 2019). Barcelona y Madrid se han reforzado como principales áreas metropolitanas del país y actúan como centros económicos, financieros, logísticos y de innovación. Si bien Madrid destaca por su especialización en el sector financiero y su capacidad de atraer sedes empresariales, en Barcelona hay un mayor peso de la industria y se está constituyendo como un destacado centro del sur de Europa para las inversiones en el ámbito de las nuevas tecnologías y la creación de start-ups (Sorando \& Leal, 2019). Ello está comportando la llegada de población con niveles de cualificación cada vez más elevados, y de ingresos medios y altos: mientras Barcelona se ha especializado en la atracción de población cualificada internacional, en Madrid los flujos de población espańola con alto nivel de instrucción no han hecho más que crecer en los últimos años (González-Leonardo et al., 2019; López-Gay \& Andújar-Llosa, 2020). A este fenómeno se une, además, la turistización de la ciudad, que no solo repercute en la especialización en determinadas actividades económicas, sino que también contribuye a tensionar el mercado de la vivienda por el cambio de una parte del stock a uso turístico (Cocola-Gant, 2016).

Es en este contexto de aumento de precios de la vivienda, creciente dificultad de acceso a ella e incremento de la selección sociodemográfica de los flujos residenciales 
y migratorios, que se enmarca esta contribución. Más concretamente, nuestro objetivo es conocer las dinámicas de funcionamiento del mercado de la vivienda y los efectos que ha tenido sobre la población del barrio de Sant Antoni en Barcelona. Este barrio, que pese a su centralidad había permanecido ajeno a episodios previos de fuerte transformación urbana y sociodemográfica, se ha convertido en los últimos años en el epicentro de los procesos de gentrificación (Caballero, 2018). No es el único barrio que padece dichos procesos, pero sí ha adquirido una fuerte carga simbólica dentro de la ciudad (López-Gay, 2018). Su localización -en el centro de la urbe-, las características de su parque de viviendas -pisos grandes, a menudo en régimen de alquiler en fincas de propiedad vertical-, y la aparición de los fondos de inversión internacionales que buscan nuevos activos para incorporar al mercado residencial y turístico, lo han convertido en un espacio cada vez más atractivo. Partimos de la hipótesis de que el barrio atrae a una creciente población con niveles educativos y socioprofesionales elevados, que alimenta procesos de desplazamiento y expulsión de la población con menos ingresos. Como consecuencia, se experimenta una transformación significativa de la composición de la población hacia una elitización de la misma. Esta dinámica es vista por los residentes como una amenaza a la cohesión social, al tejido asociativo y al fuerte sentido de comunidad e identidad del barrio.

Consideramos que la experiencia de Sant Antoni es relevante desde una perspectiva más amplia, que va más allá de este barrio barcelonés, ya que en ella se manifiestan dinámicas emergentes poco estudiadas, como la turistización o la inmigración internacional cualificada, aspectos que necesitan ser incorporados para entender los procesos de gentrificación actuales del sur de Europa. De forma específica, en esta contribución se exponen los resultados del análisis realizado a partir de tres ejes principales: i) la evolución y el perfil sociodemográfico de los flujos residenciales y migratorios, que permiten identificar las características de los nuevos vecinos, los procesos de desplazamiento de la población y el cambio de la composición de la población del barrio; ii) el papel del mercado de la vivienda, sobre todo a través de la evolución de los precios; y iii) el testimonio de los nuevos y viejos vecinos, que permiten identificar, por un lado, los atractivos del barrio y las motivaciones de los nuevos residentes, y por el otro, los mecanismos de expulsión de la población. Para la realización de este estudio se ha combinado el análisis cuantitativo de fuentes sociodemográficas, con un trabajo de campo que ha consistido en la realización de entrevistas semiestructuradas a vecinos y antiguos residentes, así como en prácticas de observación en diferentes entidades sociales del barrio.

\section{Vivienda, desplazamiento y migración internacional cualificada en los procesos de gentrificación}

El marco conceptual general en el que circunscribe este trabajo es el de la gentrificación. Se trata de un proceso definido hace más de cincuenta años y que desde entonces ha sido abordado desde disciplinas muy diversas. El punto de convergencia de las diferentes aproximaciones y que encontramos en la formulación original pone el foco en los procesos de sustitución sociodemográfica de los barrios, un proceso 
vinculado a la llegada de población de estratos socioeconómicos medios y altos que provoca el desplazamiento de la población más vulnerable, con ingresos más bajos (Glass, 1964). En el contexto de producción capitalista del espacio urbano, la gentrificación se entiende como una estrategia para la desposesión que genera la apropiación de las rentas del suelo por parte de una minoría (Benach \& Albet, 2018). El papel clave de la renta del suelo fue destacado desde el origen de su conceptualización, pero fue reconstruido más tarde bajo la hipótesis del diferencial de renta (rent gap), que vendría a explicar los ciclos de desvalorización o destrucción del valor a los que está sujeto todo suelo urbano (Smith, 1979). En estas fluctuaciones, consecuencia de estrategias de inversión y desinversión, participan diversos agentes urbanos, que van desde la intervención pública a través de, por ejemplo, el diseño e impulso de planes de regeneración urbana, hasta la participación de agentes privados, como promotores, entidades financieras y fondos de inversión, nacionales e internacionales. La financiarización de la vivienda es un aspecto clave en la producción del espacio urbano contemporáneo y, por tanto, en las dinámicas gentrificadoras más recientes (Aalbers, 2019). Especialmente desde la crisis de 2008, los desahucios de inquilinos y de propietarios que no pueden hacer frente a las hipotecas han desempeñado un papel importante en Espańa como mecanismo previo al desplazamiento de población y a la gentrificación de los barrios (VivesMiró et al., 2015). A los desahucios se une una inseguridad residencial en aumento, asociada a las crecientes dificultades en el pago de la vivienda (Módenes, 2019). Ambas dinámicas estarían vinculadas a un empeoramiento de las condiciones de salud, tanto física como mental, así como al debilitamiento y desarticulación de las redes sociales de proximidad (Vásquez-Vera et al., 2019).

Consideramos que es imprescindible entender la forma de producir espacio urbano en el actual contexto capitalista para explicar las transformaciones de nuestro caso de estudio, pero en este trabajo remarcamos también la necesidad de considerar el papel de la llegada de migrantes cualificados para comprender los cambios actuales en la composición de la población en las principales ciudades globales occidentales (Musterd et al., 2016). Las áreas urbanas son la punta de lanza de la creciente diversidad y complejidad en la relación entre los movimientos migratorios, los lugares de trabajo y la residencia en ciudades cada vez más globales (Sassen, 2011). En ese contexto de hipermovilidad actual, han aparecido perfiles de inmigrantes que valoran especialmente el bienestar y la calidad de vida que puede ofrecer el destino residencial (Benson \& O’Reilly, 2009). El influjo de población migrante transnacional de estratos socioeconómicos medios y altos puede desempeñar un papel fundamental en la transformación de los ámbitos urbanos, creando nuevas posibilidades para la inversión del capital en el mercado de la vivienda (Sigler \& Wachsmuth, 2015). Una parte de este colectivo destaca por su naturaleza especialmente transitoria. Ejemplos de estos perfiles son los estudiantes de intercambio o de posgrado, o los denominados nómadas digitales, individuos cuya actividad profesional no está vinculada a un lugar en particular y que muestran un nivel de transitoriedad muy elevado. Estos perfiles tan móviles han crecido en el contexto de dos tendencias globales: la hipermovilidad y la digitalización (Thompson, 2018). Al igual que en otras áreas del sur de Europa, las ciudades españolas están recibiendo 
un número creciente de poblaciones privilegiadas transitorias (Jover \& Díaz-Parra, 2019; Quaglieri, 2020). El asentamiento de estos grupos en ciertas áreas urbanas y el impacto de salarios superiores al de los locales pueden causar tensiones en el mercado inmobiliario (White \& Hurdley, 2003).

En el extremo de la volatilidad encontramos a población que permanece en la ciudad únicamente unos días, los turistas. Estos han adquirido notabilidad en los estudios de transformación urbana sobre todo en el momento en que ha habido un cambio de uso de algunas viviendas y, por tanto, un trasvase de stock de uso residencial a turístico, un proceso potenciado por las plataformas electrónicas de alquiler turístico (Cocola-Gant, 2016). En la última década han proliferado los trabajos sobre la penetración y expansión de este tipo de alojamientos en ciudades de todo el mundo, así como las consecuencias de la presión del turismo en entornos urbanos. Cada vez son más los científicos sociales que ven necesario indagar en estos fenómenos para comprender la configuración socioespacial de las ciudades del siglo xxi (Slee, 2017; Wachsmuth \& Weisler, 2018). La literatura internacional advierte de los efectos que el turismo tiene en los tejidos urbanos y sociales: impone estrés al mercado inmobiliario (García-López et al., 2019); transforma aspectos del entorno urbano como la movilidad, el espacio público y la actividad comercial (Blázquez-Salom et al., 2019); y refuerza los procesos de desplazamiento de las poblaciones locales más vulnerables, una dinámica que algunos autores han conceptualizado como gentrificación turística (Cocola-Gant, 2018; Gotham, 2005). Las transformaciones asociadas a la actividad turística se pueden retroalimentar con las vinculadas a la gentrificación transnacional, anteriormente explicada (Cocola-Gant \& López-Gay, 2020).

En la actualidad, pese a que se admite que los procesos de gentrificación son globales y han llegado a todos los rincones del planeta (Lees et al., 2016), se sigue contemplando la especificidad regional de dichos procesos (Janoschka et al., 2014). En España, los procesos de gentrificación se habían circunscrito hasta la crisis de 2008 a espacios urbanos muy específicos, sobre todo a ciertos centros históricos que habían experimentado una fuerte degradación durante las últimas décadas del siglo xx (Sorando \& Ardura, 2018), en un contexto residencial en que la suburbanización era el fenómeno protagonista. Tras la crisis, las áreas que experimentan procesos de gentrificación se expanden y se multiplican de la mano de una mayor representación de las clases medias en los flujos hacia los centros urbanos, alcanzando barrios que, pese a tener una elevada centralidad, habían permanecido relativamente ajenos a estos procesos (López-Gay et al., 2019). En esta expansión se ha subrayado el impacto notable de la migración cualificada, ya sea nacional o transnacional (LópezGay \& Andújar-Llosa, 2020). Como contrapartida, se ha observado una tendencia general hacia la suburbanización de la pobreza, vinculada a la expulsión de los hogares de bajos ingresos desde los centros urbanos y espacios gentrificados (Bailey \& Minton, 2018; Hochstenbach \& Musterd, 2018). 


\section{Metodología}

El estudio se centra en el caso de Sant Antoni, uno de los 73 barrios que conforman el municipio de Barcelona (Figura 1). El barrio está situado en el distrito del Eixample de Barcelona, forma parte de la expansión urbana planificada de la segunda mitad del siglo xix y limita con el centro histórico. Tiene una población de 38.182 habitantes, una extensión de 80,5 hectáreas y una densidad de población de 479 hab/há.

\section{Figura I | Contexto territorial del barrio de Sant Antoni}
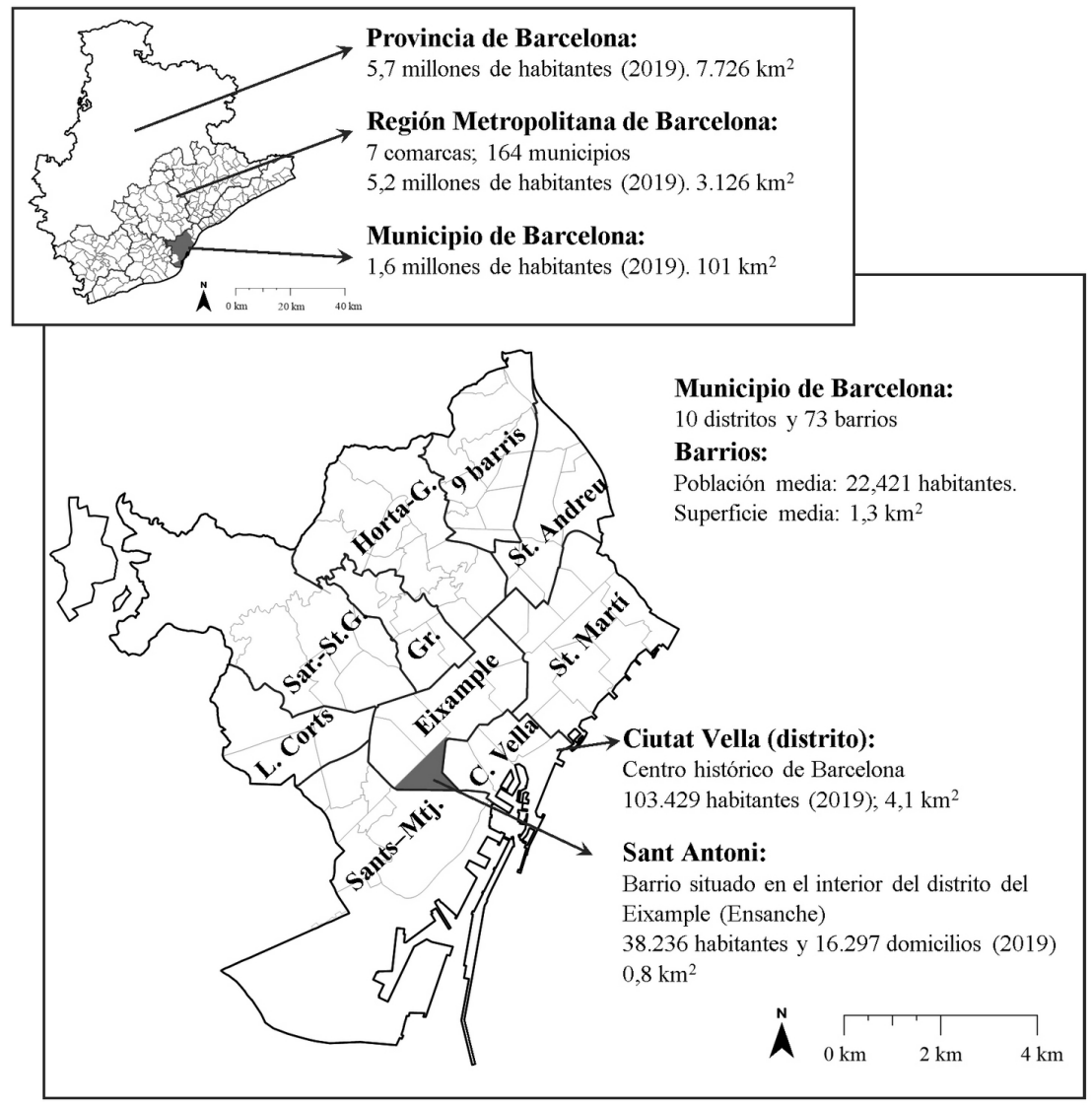

FUENTE: ELABORACIÓN PROPIA

El análisis del apartado cuantitativo se alimenta principalmente del registro de altas, bajas y cambios de domicilio del Padrón Continuo del Ayuntamiento de Barcelona, correspondiente al periodo 2011-2018. Además de las principales variables demográficas contenidas en el padrón (sexo, edad, nacionalidad, ámbito de nacimiento), el consistorio municipal nos ha proporcionado el origen y destino de los movimientos 
y el nivel de instrucción declarado por la persona en el momento de formalizar el cambio residencial. La inclusión de esta variable socioeconómica es novedosa en este tipo de aproximaciones a partir de datos de flujos, ya que no aparece en fuentes de datos tradicionales para el estudio de la movilidad residencial en Espańa, como la Estadística de Variaciones Residenciales. Pese a que la expansión educativa de las últimas décadas ha debilitado la relación entre el nivel de estudios y la condición socioeconómica, la correlación del primero con el nivel de ingresos es todavía muy fuerte (Ministerio de Educación y Formación Profesional [MEFr], 2020). Además de incorporar dicho dato, para describir este tipo de procesos la literatura sobre gentrificación se apoya en otras dimensiones individuales y familiares, como el capital social o cultural, también altamente correlacionadas con el nivel de estudios.

Hemos adoptado diversas estrategias metodológicas para medir los fenómenos abordados, pero sobre todo hemos creado indicadores simples que permiten describir el perfil de la población que se desplaza en el territorio por motivos residenciales, y su evolución en el tiempo. Gracias a los datos de ingresos medios a nivel inframunicipal del Instituto Nacional de Estadística (INE), hemos podido discernir entre cambios de residencia con destino a barrios con más y menos ingresos medios por persona que los de Sant Antoni. También hemos utilizado los datos del Padrón Continuo del Ine para reconstruir las generaciones de residentes en el barrio entre 2013 y 2018 y los datos sobre precios del mercado de la vivienda, de compra y alquiler, los cuales son de acceso público en la página web del Departamento de Estadística del Ayuntamiento de Barcelona.

El trabajo de campo correspondiente a la parte cualitativa se llevó a cabo durante el año 2018. Se entrevistó a 33 personas ( 19 mujeres y 14 hombres), pertenecientes a tres grupos distintos (Tabla 1): residentes de toda la vida en el barrio, residentes llegados durante los últimos diez años, y personas que han abandonado recientemente el barrio y ahora viven en otro barrio o municipio de la metrópolis.

TABla I | Personas entrevistadas por sexo y residencia

\begin{tabular}{|l|c|c|c|}
\cline { 2 - 4 } \multicolumn{1}{c|}{} & HOMBRES & MUJERES & TOTAL \\
\hline Residentes (RES) & 4 & 4 & 8 \\
\hline Residentes llegados últimos diez años (IN) & 8 & 7 & 15 \\
\hline Personas que se han marchado del barrio (OUT) & 2 & 8 & 10 \\
\hline Total & 14 & 19 & 33 \\
\hline
\end{tabular}

FUENTE: ELABORACIÓN PROPIA A PARTIR DEL TRABAJO DE CAMPO (20I8)

La edad de las personas entrevistadas es variada. Se observa que las más jóvenes (más formadas y con una mayor proporción de extranjeros) llevan menos tiempo residiendo en el barrio y comparten con mayor frecuencia vivienda con otras personas, generalmente de la misma edad. Mientras, los adultos de más edad, todos españoles, pertenecen al grupo que lleva más tiempo residiendo en el barrio, no comparten piso y no tienen estudios tan altos como los recién llegados (Tabla 2). 
TABla 2 Perfil de las personas entrevistadas

\begin{tabular}{|c|c|c|c|c|}
\hline & RES & IN & OUT & TOTAI \\
\hline \multicolumn{5}{|l|}{ SEXO } \\
\hline Mujeres & 4 & 7 & 8 & 19 \\
\hline Hombres & 4 & 8 & 2 & 14 \\
\hline \multicolumn{5}{|l|}{ EDAD } \\
\hline$<30$ ańos & 0 & 4 & 4 & 8 \\
\hline $31-40$ & 2 & 8 & 4 & 14 \\
\hline >40 ańos & 6 & 3 & 2 & 11 \\
\hline \multicolumn{5}{|l|}{ NIVEL DE ESTUDIOS } \\
\hline Secundaria & 5 & 0 & 1 & 6 \\
\hline Estudios superiores (grado) & 3 & 6 & 4 & 13 \\
\hline Estudios superiores (posgrado) & 0 & 9 & 5 & 14 \\
\hline \multicolumn{5}{|l|}{ NACIONALIDAD } \\
\hline Espańola & 8 & 9 & 9 & 26 \\
\hline Extranjera & 0 & 6 & 1 & 7 \\
\hline \multicolumn{5}{|l|}{ COMPOSICIÓN DEL HOGAR } \\
\hline 1 persona & 1 & 1 & 3 & 5 \\
\hline 2 personas & 2 & 3 & 2 & 7 \\
\hline $3-4$ personas & 5 & 3 & 2 & 10 \\
\hline Comparte piso & 0 & 8 & 3 & 11 \\
\hline Piso de propiedad & 4 & 5 & 2 & 11 \\
\hline Piso de alquiler & 4 & 10 & 8 & 22 \\
\hline $\begin{array}{l}\text { RES: RESIDENTES; IN: R } \\
\text { MARCHADO DEL BARRI }\end{array}$ & $S$ LLEC & MOS & OUT: & QUE SI \\
\hline
\end{tabular}

El guion de entrevista giró en torno a, por una parte, la historia residencial, el sentido de pertenencia, la vida cotidiana, la red de relaciones y la vinculación con el tejido asociativo del barrio; por otra, la valoración del barrio, la visión de la transformación del mismo y las perspectivas de futuro, para terminar con la calidad de vida y la satisfacción vital. Las entrevistas se hicieron en distintos lugares del barrio y se realizaron en catalán, alguna en castellano y una en inglés. Las entrevistas se grabaron, se transcribieron en su totalidad y fueron codificadas con el software informático Atlas-Ti.

Para complementar estos testimonios, se entrevistó a miembros de la Asociación de Vecinos y Vecinas de Sant Antoni y del colectivo vecinal Fem Sant Antoni (Hagamos Sant Antoni). Durante el transcurso del trabajo de campo asistimos de forma regular a las asambleas, abiertas al público, de este colectivo y del Sindicat de Llogateres (Sindicato de Inquilinas), que lucha contra los procesos de expulsión de vecinos del barrio. Esta observación nos permitió conocer en detalle los casos reales de desahucio, observar su impacto en la vida de las personas y acercarnos a las respuestas y estrategias que los colectivos ofrecían para hacer frente a los desahucios y otros conflictos relacionados con la vivienda. 


\section{Resultados}

Hemos estructurado la presentación de los resultados empíricos en dos grandes apartados: analizamos primero la transformación sociodemográfica de Sant Antoni a través de los datos cuantitativos; en segundo lugar, incorporamos los resultados del análisis cualitativo. Los dos apartados presentan una estructura similar y se centran inicialmente en el perfil de los nuevos vecinos, para profundizar posteriormente en los movimientos de salida del barrio.

\section{Los cambios en la composición sociodemográfica: hacia una elitización transnacional creciente}

Según las fianzas depositadas en el Institut Català del Sòl (INCAsòl - Instituto Catalán del Suelo), un alquiler medio en Sant Antoni ha pasado de costar 693 euros al mes al inicio de 2014 a 986 euros a comienzos de 2019, lo que representa un aumento del $42,3 \%$ en un periodo de cinco ańos, ligeramente por encima de la media barcelonesa $(40,1 \%)$. En la Figura 2 representamos los precios de venta de vivienda usada (incluyen prácticamente la totalidad de las transacciones en Sant Antoni) y de alquiler $\left(€ / \mathrm{m}^{2}\right)$ para el barrio de estudio y para el conjunto de la ciudad. El aumento de los precios es vertiginoso desde 2014. Por otro lado, según los datos de la Encuesta Sociodemográfica de Barcelona de 2017, el 43,9\% de la población del barrio residía bajo régimen de alquiler (el 58,3\% de la población de 25 a 49 ańos), seis puntos porcentuales más que en el resto de la ciudad. La proporción de inquilinos en Sant Antoni en 2017 es notablemente superior a la de tan solo seis ańos antes, en 2011, cuando representaban el 36,5\% de la población del barrio.

Los datos procedentes de las altas padronales -inscripción de personas empadronadas en el municipio- apuntan a que más de la mitad de las entradas al barrio se concentran en la franja de edad de adultos jóvenes, de 25 a 39 años de edad (Figura 3-a). Aunque la concentración en estas edades es un rasgo común de la movilidad residencial y de las migraciones, el peso que adquieren en Sant Antoni es superior al del conjunto barcelonés, en detrimento de las entradas de población infantil y de mayores de 65 años. Por otro lado, es una población con un elevado nivel de instrucción, por encima de la media de Barcelona y que ha ido en aumento a lo largo de la década. Casi dos de cada tres personas de 25 a 39 ańos que han llegado al barrio entre 2016 y 2018 tienen estudios universitarios, mientras que al comienzo de la década esa cifra se situaba por debajo del 50\% (Figura 3-b). Finalmente, la población nacida en el extranjero con estudios universitarios está cada vez más representada en los flujos de entrada al barrio. En 2018, el 39,4\% de las entradas al barrio ( $\geq 25$ ańos) corresponde a personas nacidas en el extranjero con estudios universitarios, mientras que en 2011 estas representaban el 24,7\% de todas las llegadas (Figura 3-c). 
FIGURA 2 | Evolución del precio de compra (usado) y alquiler en el barrio de Sant Antoni y en el municipio de Barcelona, 2011-2019

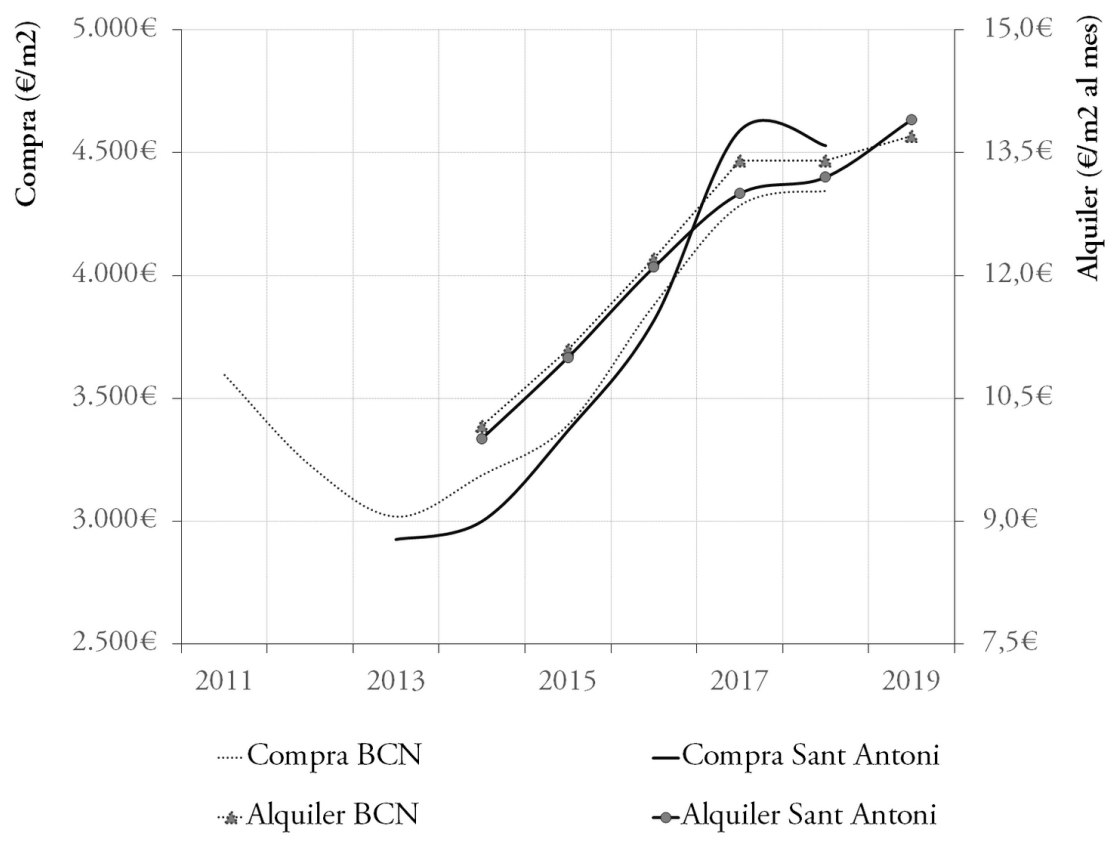

FUENTE: ELABORACIÓN PROPIA A PARTIR DE LOS DATOS SOBRE MERCADO DE LA VIVIENDA, AJUNTAMENT DE BARCELONA

\section{Figura 3 | Composición de los flujos de entrada al barrio de Sant Antoni, Barcelona. 2011-2018}

(a) Distribución de los flujos de entrada(2011-2018) según grupo de edad (Sant Antoni y Barcelona)

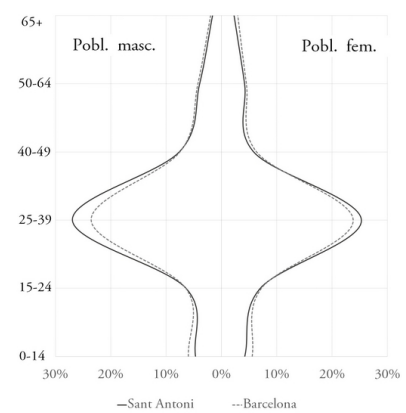

(b) Proporción de población con estudios universitarios en los flujos de entrada según edad y periodo (St. Antoni y Barcelona) (c) Evolución de los flujos de entrada a Sant Antoni según nivel de instrucción y lugar de nacimiento
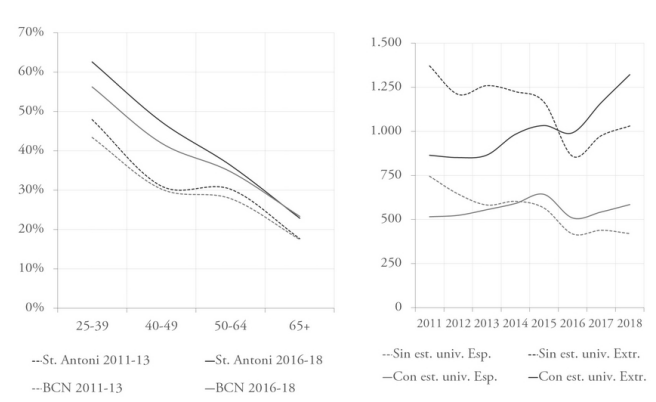

NOTA: SE INCLUYEN TODOS LOS TIPOS DE ENTRADA (DESDE OTROS BARRIOS, OTROS MUNICIPIOS Y otros PAÍSES)

FUENTE: ELABORACiÓN PROPIA A PARTIR DEL REgISTRO DE CAMBIOS DE DOMICILIO Y ALTAS RESIDENCIALES. AJUNTAMENT DE BARCELONA 
La transformación, a lo largo de la década, del perfil de la población que ha llegado al barrio, por tanto, ha sido intensa y veloz. Sant Antoni es el quinto barrio de la ciudad (de un total de 73) en el que más ha cambiado el nivel educativo de la nueva población (Tabla 3). Pese a que en 2011 la población que llegaba al barrio ya presentaba un perfil educativo medio -cuatro de cada diez de los nuevos vecinos de entre 25 y 49 ańos tenían estudios universitarios-, los valores de 2018 se sitúan por encima del $60 \%$.

TABLA 3 | Evolución de la proporción de población con estudios universitarios en los flujos de entrada (población 25-49 ańos). Ranking de los diez barrios con mayor diferencia entre 2011 y 2018

\begin{tabular}{|c|c|c|c|c|c|c|c|c|c|}
\hline & & & \\
\hline & $\begin{array}{c}201 \text { I I } \\
(\%)\end{array}$ & $\begin{array}{c}2015 \\
(\%)\end{array}$ & $\begin{array}{c}2018 \\
(\%)\end{array}$ & $\begin{array}{c}\text { DIF. } \\
\text { (P.P.) }\end{array}$ & & $\begin{array}{c}201 \text { I } \\
(\%)\end{array}$ & $\begin{array}{c}2015 \\
(\%)\end{array}$ & $\begin{array}{c}2018 \\
(\%)\end{array}$ & $\begin{array}{l}\text { DIF. } \\
\text { (P.P.) }\end{array}$ \\
\hline el Poble Sec & 28,6 & 41,1 & 48,6 & 20 & el Raval & 24,8 & 36,1 & 43,5 & 18,8 \\
\hline el Poblenou & 43,9 & 54 & 63,5 & 19,6 & $\begin{array}{l}\text { el Camp de } \\
\text { l'Arpa del Clot }\end{array}$ & 37,4 & 47,8 & 55 & 17,6 \\
\hline Can Baró & 32,3 & 43,4 & 51,5 & 19,2 & Sants-Badal & 30,8 & 40,5 & 48,1 & 17,3 \\
\hline Hostafrancs & 32,3 & 45,3 & 51,5 & 19,1 & $\begin{array}{l}\text { la Nova Esquerra } \\
\text { de l'Eixample }\end{array}$ & 50,3 & 60,4 & 67,5 & 17,1 \\
\hline Sant Antoni & 42,1 & 52,4 & 60,8 & 18,8 & $\begin{array}{l}\text { la Font de la } \\
\text { Guatlla }\end{array}$ & 39,9 & 45,7 & 56,8 & 16,9 \\
\hline
\end{tabular}

NOTA: SE INCLUYEN TODOS LOS TIPOS DE ENTRADAS

FUENTE: ELABORACIÓN PROPIA A PARTIR DEL REGISTRO DE CAMBIOS DE DOMICILIO Y ALTAS RESIDENCIALES. AJUNTAMENT DE BARCELONA

Por lo que respecta a los cambios de vivienda generados en el barrio, la intensidad con que la población ha cambiado de vivienda no se ha incrementado a lo largo de la década (Figura 4). El descenso ha sido muy notable entre la población nacida en el extranjero, probablemente por un efecto del propio proceso de asentamiento de los flujos inmigratorios que llegaron a lo largo de la década anterior (Bayona \& López-Gay, 2011) y de un aumento progresivo del peso de la población más cualificada, con trayectorias residenciales menos inestables. La tasa de movilidad residencial también ha descendido ligeramente entre la población nacida en España. En este caso, el descenso ha sido más evidente entre la población adulta más joven. Entre otros, aquí podríamos pensar en un posible efecto de postergación de los movimientos de emancipación o de reajuste residencial debido a las crecientes dificultades en el acceso a la vivienda. Entre la población adulta de edad más avanzada, en cambio, la movilidad ha aumentado ligeramente. Cuando ańadimos el tipo de destino, observamos cambios muy notables a lo largo de la década. El movimiento que más ha decrecido ha sido el intrabarrial, aquel de quienes permanecen en Sant Antoni. La frecuencia con que la población nacida en Espańa realiza este tipo de movimiento ha descendido un $25 \%$ entre el primer y el último periodo. La probabilidad de realizar un cambio a otros barrios de la ciudad con mayores ingresos (movimientos agrupados en la categoría 'Interbarrial $\uparrow$ ') ha descendido un 18\%, mientras que la de marchar a un barrio con ingresos más bajos ('Interbarrial $\downarrow$ ') solo lo ha hecho en un $6 \%$. En cambio, la intensidad de la movilidad residencial hacia 
otros municipios de la provincia de Barcelona se ha incrementado en un 9\%. Entre la población nacida en el extranjero la pauta es parecida: los movimientos que más han decrecido son los de permanencia en el barrio y los que menos, los de salida a otros municipios.

FIgURA 4 | Tasas de movilidad residencial según edad, periodo, destino del movimiento y ámbito de nacimiento. Barrio de Sant Antoni, 20112013 vs. $2016-2018$

Población nacida en España

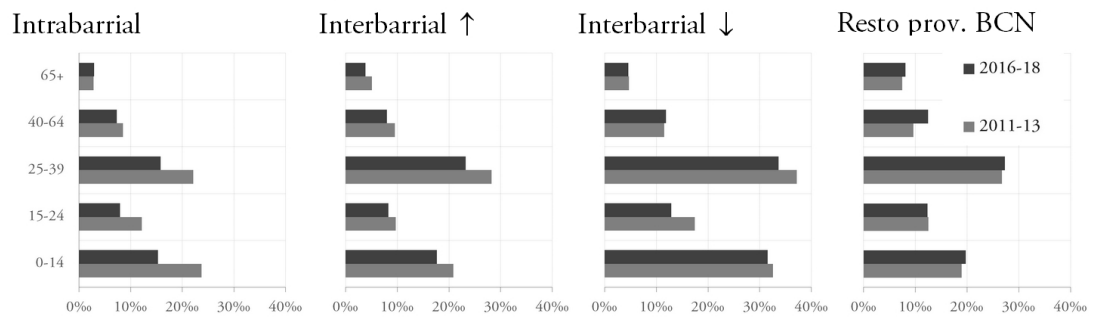

Población nacida en el extranjero

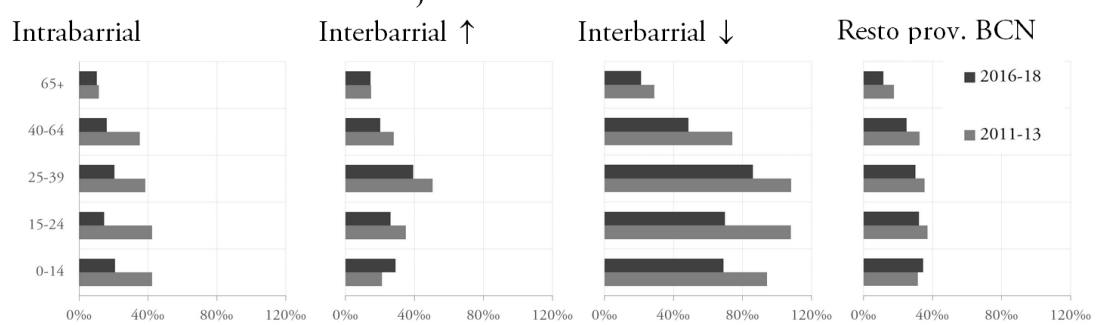

NOTA: LA CATEGORÍA 'INTERBARRIAL $\uparrow$ ' INCLUYE LOS MOVIMIENTOS CON DESTINO A OTRO BARRIO CON INGRESOS MEDIOS POR PERSONA SUPERIORES A LOS DE SANT ANTONI. EN CAMBIO, 'INTERBARRIAL $\downarrow$ ' INCLUYE AQUELLOS QUE SE DIRIGEN A UN BARRIO DE MENOR INGRESO

FUENTE: ELABORACIÓN PROPIA A PARTIR DEL REGISTRO DE CAMBIOS DE DOMICILIO Y BAJAS RESIDENCIALES. AJUNTAMENT DE BARCELONA

Para poder incluir el nivel educativo de la población en el análisis de las salidas del barrio debemos renunciar a la elaboración de tasas de movilidad residencial, debido a la naturaleza de los datos. Sí podemos analizar, en cambio, la distribución de los movimientos según el destino del cambio de vivienda. En este caso, la hemos calculado para la población de 25 a 49 ańos, franja en la que se concentra la mayor parte de los cambios (Figura 5). Los resultados muestran un decrecimiento del peso de los cambios de vivienda que permanecen en el barrio, sobre todo entre la población menos formada. La población más formada ha disminuido en menor medida sus probabilidades de permanecer en el barrio una vez iniciado el cambio de vivienda. Entre la población nacida en España, el peso de los movimientos a otros barrios de la ciudad ha permanecido estable para la población con estudios universitarios, pero ha decrecido para la población sin ese nivel de instrucción. En un mercado de la vivienda más restrictivo, sobre todo en las zonas con mayores 
ingresos, han aumentado los movimientos hacia sectores con peor nivel de ingresos que los de partida. Finalmente, el peso de los movimientos que abandonan la ciudad central ha aumentado de forma muy notable para la población espańola sin estudios universitarios (11 puntos porcentuales), y ya representa el $36,7 \%$ de todos los movimientos entre 2016 y 2018. Estos movimientos apenas han aumentado cuatro puntos porcentuales ( $22,7 \%$ en el último periodo) para la población con estudios universitarios. La población del barrio con mayor instrucción ha resistido más el aumento del precio del mercado de la vivienda, permaneciendo en mayor medida en el barrio y en el municipio que la población con menos formación. Entre la población extranjera sin estudios universitarios, el peso de los movimientos intrabarriales se ha reducido (en 2016-2018 solo representan el 11,7\%) y el de los intermunicipales ha aumentado. Los extranjeros más educados siguen siendo los menos propensos a abandonar el municipio central.

Figura 5 | Distribución del destino de los flujos residenciales generados en el barrio de Sant Antoni según lugar de nacimiento y nivel de estudios. Población de 25-49 ańos, 2011-2013 vs. 2016-2018

Población nacida en España

$$
\begin{aligned}
& 50 \% \\
& 45 \% \\
& 40 \% \\
& 35 \% \\
& 30 \% \\
& 25 \% \\
& 20 \% \\
& 15 \% \\
& 10 \% \\
& 5 \% \\
& 0 \%
\end{aligned}
$$

$$
2011-13
$$

Sin estudios universitarios

$$
\text { Intrabarrio }
$$

\section{Población nacida en el extranjero}

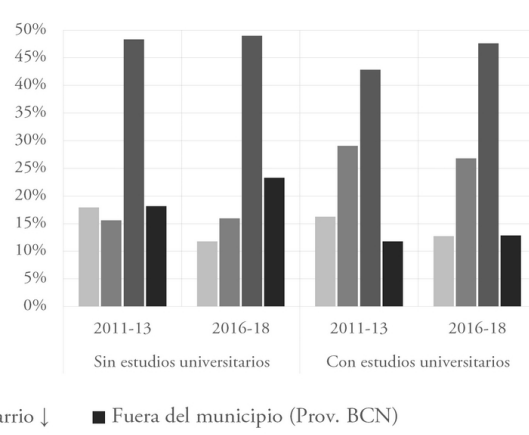

FUENTE: ELABORACIÓN PROPIA A PARTIR DEL REGISTRO DE CAMBIOS DE DOMICILIO Y BAJAS RESIDENCIALES. AJUNTAMENT DE BARCELONA

Finalmente, comparamos los cambios en la distribución de los destinos entre Sant Antoni y el conjunto de barrios de Barcelona, para poder valorar si este es un hecho común para toda la ciudad o específico para el ámbito de estudio (Figura 6). La reducción del peso de los movimientos intrabarriales se ha registrado también en el conjunto de los barrios de la ciudad, sobre todo para la población con menos estudios, pero en Sant Antoni el descenso se ha experimentado con más intensidad, sobre todo entre la población nacida en Espańa y entre los extranjeros sin estudios. En cambio, el aumento de los movimientos de salida del municipio ha sido más pronunciado para los que partían de Sant Antoni, sobre todo para los nacidos en España y con menor nivel educativo. 
FIGURA 6 | Diferencia relativa (\%) entre 2016-2018 y 2011-2013 de la distribución de los destinos de los flujos residenciales según tipo de destino y nivel de estudios. Población de 25-49 ańos, barrio de Sant Antoni y conjunto de Barcelona

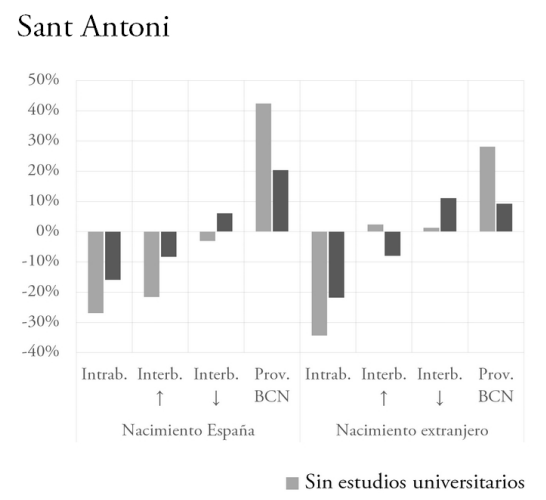

Municipio de Barcelona

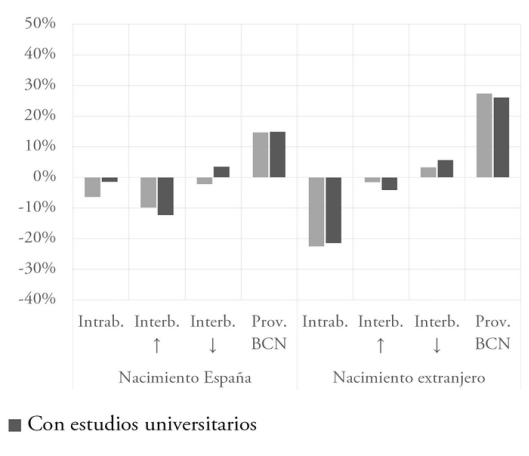

FUENTE: ELABORACIÓN PROPIA A PARTIR DEL REGISTRO DE CAMBIOS DE DOMICILIO Y BAJAS RESIDENCIALES. AJUNTAMENT DE BARCELONA

Tras constatar el fortalecimiento de la selectividad residencial y migratoria según el nivel de estudios de los flujos de entrada y salida en Sant Antoni, analizamos las consecuencias en la composición de la población del barrio. Con una población alrededor de los 38.000 habitantes, el número de residentes ha permanecido prácticamente estable durante toda la década. Esta aparente estabilidad esconde cambios importantes en la estructura por edad y origen de la población. El seguimiento de las generaciones entre 2013 y 2018 permite identificar un intenso reemplazo generacional y de origen (Figura 7). El barrio ha ganado mucha población adulta de las franjas más jóvenes, sobre todo la nacida fuera de la provincia de Barcelona, en Europa y en América. En cambio, se pierde población local, como ya se apuntaba en el análisis de los flujos. Por otro lado, se pierde población de edad adulta más avanzada de la mayor parte de orígenes. Es interesante el caso de la población nacida en América, ya que se ganan muchos efectivos de edad adulta-joven y se pierden otros tantos de edad más avanzada. Detrás de este dato no solo se esconde un proceso de reemplazo generacional, sino también de estatus socioeconómico: el 55\% de la población de 25-49 años nacida en América que abandonó el barrio durante ese periodo no tenía estudios universitarios, una cifra superior al $42 \%$ que representaba ese grupo educativo entre los llegados. Pese al incremento de la población adulta, la población infantil (de 0 a 9 años en 2013) se ha reducido -6,3\% en el quinquenio, mientras que en el conjunto de la ciudad ha permanecido estable. La relación entre adultos de 25 a 59 ańos y población infantil de 0 a 14 es de 5,2 adultos por nińo, el barrio con la cuarta relación más alta de la ciudad. Finalmente, el ritmo con el que desciende la población de más de 65 años es similar al del resto del municipio. 
FIGURA 7 | Diferencia en los efectivos generacionales (2018-2013) según lugar de nacimiento. Sant Antoni, grupo de edad en 2012
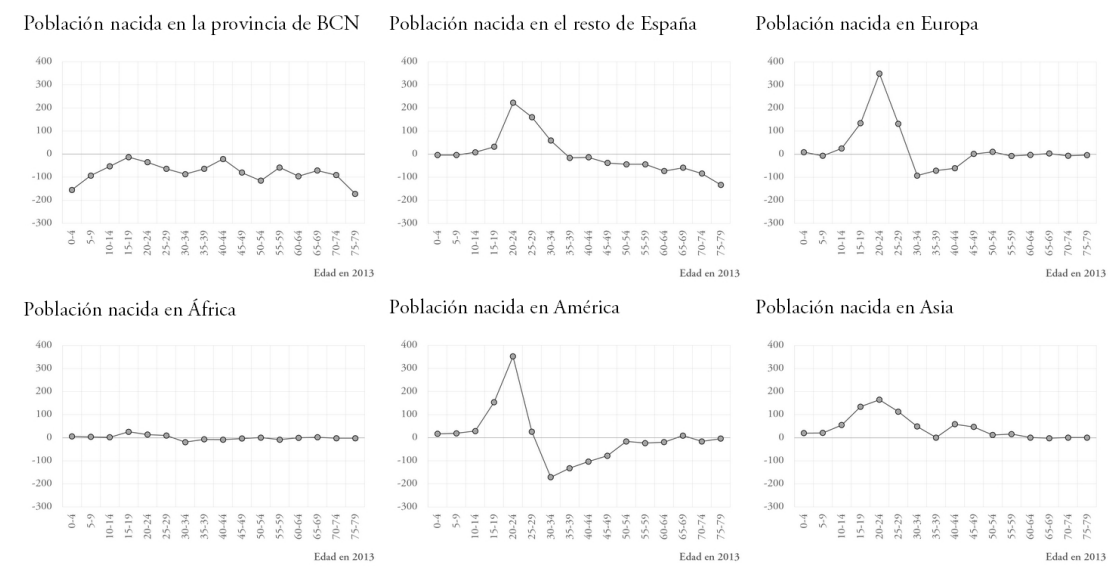

FUENTE: ELABORACIÓN PROPIA A PARTIR DEL PADRÓN CONTINUO. INSTITUTO NACIONAL DE ESTADÍSTICA (INE)

Los que llegan y los que se van: experiencias y vivencias en un barrio en proceso de elitización e incremento del precio de la vivienda

Presentamos primero el análisis sobre las motivaciones de los nuevos residentes por localizarse en Sant Antoni. "Yo estoy encantada, no me cambiaría a otro barrio". Con estas palabras, Rosa ${ }^{1}$ muestra su satisfacción por vivir en el barrio de Sant Antoni. Ella es una de las quince personas entrevistadas que llegó al barrio en los últimos años, concretamente en 2012; y, como las demás personas, lo escogió por su céntrica localización, por su accesibilidad a los servicios, equipamientos y transporte público, por la variedad del tejido comercial y por la "vida de barrio".

La "vida de barrio" es una de las expresiones más usadas por muchas de las personas entrevistadas y hace referencia a una combinación de aspectos físicos y emocionales que, juntos, provocan un sentimiento de bienestar. Los aspectos materiales están relacionados con el escenario urbano formado por las calles, los edificios, los comercios, los equipamientos necesarios para la vida cotidiana. Los aspectos inmateriales están vinculados con sensaciones subjetivas de bienestar potenciadas por las relaciones sociales que se establecen con los vecinos de la misma escalera, de edificios colindantes y del barrio, con los comerciantes de las tiendas de proximidad o con las asociaciones del barrio. Mientras que Núria destaca del barrio la cantidad de servicios y equipamientos, el transporte, la localización y la accesibilidad, a Pascal le parece un buen lugar para vivir por la calidad de vida del barrio, su localización y tejido asociativo:

Tiene todos los servicios que se necesitan, atención médica, centros cívicos, bibliotecas, centro deportivo municipal, tienes el mercado (...) tiene los servicios de transporte inmejorables, el carril bici: soy ciclista y lo valoro muy positivamente.

1 Para proteger la identidad de las personas entrevistadas utilizamos pseudónimos. 
Me gusta porque es un barrio que está estratégicamente bien situado y que tiene un tejido social que también es potente. (Núria, 29 años, residente desde 2017)

Me parece que Sant Antoni es un buen promedio entre calidad de vida y proximidad al centro (...). Lo que me gusta más es que la zona conserva aún lo que aquí llaman la vida de barrio. Los vecinos se reúnen y organizan tanto las fiestas como algún que otro evento cultural, y eso me parece muy agradable. (Pascal, 31 ańos, residente desde 2013)

Las personas que han llegado a vivir en el barrio en los últimos ańos valoran su centralidad y sienten que ahora viven "en la ciudad" y no como antes, cuando vivían en otros barrios alejados del centro urbano neurálgico. Es el caso de Rosalía, quien en los últimos años ha cambiado de residencia a menudo y ha vivido en Madrid, en el extranjero y en casa de sus padres, situada en otro barrio ("más periférico") de Barcelona. Desde 2014, cuando económicamente ha podido volver a emanciparse, reside en Sant Antoni. Para ella cambiar de barrio ha sido como mudarse de ciudad, y le ha hecho redescubrirla y crecer su sentido de pertenencia a la misma:

Verla [se refiere a Barcelona] desde otro punto de vista era como si cambiara totalmente de ciudad, era como si no tuviera nada que ver y me parece como emocionante... vivir desde otra perspectiva Barcelona, como tenerlo todo cerca me parece como increíble. (Rosalía, 39 años, residente desde 2014)

La forma en que las inmobiliarias publicitan Barcelona y sus barrios ha variado en los últimos ańos. ${ }^{2}$ Es una información dirigida cada vez más a un cliente internacional con un poder adquisitivo medio-alto o alto. Se trata de una demanda diversa, en la que se encuentran inversores (que puedan utilizar ocasionalmente la vivienda como residencia secundaria, por ejemplo) o los que residen de forma relativamente estable en la ciudad. Buscan especialmente edificios rehabilitados en su totalidad con viviendas de alto standing. Los precios se sitúan a partir de los 400.000 euros. Los elementos que aparecen repetidamente en la publicidad de estas viviendas, y que también han sido subrayados por las personas entrevistadas, son: el año de construcción de la vivienda (sobre todo fincas centenarias) y la conservación de elementos patrimoniales; la vida y la identidad de barrio; el cosmopolitismo y la multiculturalidad; el transporte público y las comunicaciones; la centralidad; la oferta de ocio y comercial; y el espacio público y la peatonalización.

En el otro lado de la balanza encontramos a la población residente que está expuesta a un cambio de vivienda y que persigue permanecer en el barrio. Este grupo acostumbra seguir distintas estrategias. Una de ellas tiene que ver con las redes familiares y de amistad en la búsqueda de vivienda, ya que facilita el acceso por debajo de los precios de mercado. El incremento del precio de la vivienda ha afectado especialmente a la población en edad de emanciparse del hogar familiar y la posibilidad de permanecer en el barrio. Se ha observado que aquellos que pueden quedarse a vivir allí lo hacen gracias a los recursos y al apoyo familiar, que se concreta

$2 \longdiv { \text { Algunos ejemplos se pueden consultar en portales electrónicos de inmobiliarias que promocionan } }$ viviendas rehabilitadas en Barcelona, como norvetben.com y elix.es [fecha de la consulta: julio 2020]. 
en la cesión de alguna vivienda familiar (por herencia, generalmente) o porque optan por compartir piso. Esta opción pasa por encontrar, junto a amigos o compańeros de piso, una vivienda de gran superficie. El precio es elevado, pero la división del importe por las diversas habitaciones reduce la cuantía del alquiler por persona y permite afrontar el pago. Así lo comenta Pep. Sus amigos han podido quedarse en el barrio compartiendo piso y pagando entre 300 y 400 euros por una habitación. Él, en cambio, quería vivir solo y por eso tuvo que abandonar Sant Antoni.

Una de las entrevistadas comenta que se puede hablar de un mercado de habitaciones -no de viviendas-, sobre todo para jóvenes y personas que hacen estancias temporales en la ciudad -no turistas-, ya que el acceso a un piso entero es inasumible para muchas personas, no solo para los más jóvenes. En una entrevista mantenida con un miembro de Fem Sant Antoni, se comentó que existen pisos que rentan todas las habitaciones de forma ilegal. Concretamente, se hacía referencia a un piso de cuatro habitaciones alquiladas por 700 euros, del que obtenían, por tanto, 2.800 euros al mes, un importe superior al que se recibiría en el mercado libre por el apartamento entero.

Otra opción observada es la cesión del piso de alquiler a los hijos cuando los padres se jubilan y se van a vivir fuera de la ciudad. Esta opción, sin embargo, no termina siempre bien. Sería el caso de Lina, que llevaba viviendo en Sant Antoni desde los cinco años de edad, en el mismo piso en el que sus padres fueron a vivir cuando ella era pequeña. El contrato de alquiler estaba a nombre de sus padres, que una vez jubilados regresaron a su pueblo de origen. Ella se quedó en él mientras estudiaba en la universidad. Por ese entonces, los hijos de los propietarios heredaron la finca donde Lina vivía y la vendieron. Cuando ella recibió un burofax en el que le comunicaban que no le renovarían el contrato, se dirigió primero a la Oficina de l'Habitatge del Ayuntamiento de Barcelona, donde le dijeron que no podía alegar nada, y días más tarde recurrió al Sindicat de Llogateres, igualmente sin resultados. Afirma tener sentimientos contradictorios, entre rabia y pena, cuando pasea por el barrio: de rabia, porque se sintió expulsada; y de pena, porque no reconoce parte del paisaje urbano actual del barrio y eso le provoca un sentimiento de desapego. Durante meses buscó vivienda en el barrio, pero no encontraba ninguna por debajo de los 1.000 euros. Esta situación le generó un fuerte estrés, ya que suponía alterar sus planes vitales y entrar en una situación de mucha inseguridad. Actualmente, Lina está viviendo en otro barrio de Barcelona.

Preocupación, rabia, pena, impotencia... compartidas por las personas que han tenido que abandonar el barrio cuando no se les renovó el contrato de alquiler o porque el aumento de los precios les hizo desistir de quedarse. Noemí, que llevaba once años residiendo en el barrio y compartiendo piso con tres personas más, asumió con pena que debía buscar vivienda en otro lugar. La encontró en la periferia de Barcelona y la comparte con una amiga. Se siente afortunada, porque unos amigos de sus padres le alquilaron un piso y esto le facilitó el proceso de cambio.

La inseguridad residencial es mucho más marcada en las personas arrendatarias. En estos casos, las personas entrevistadas que han marchado del barrio mencionan tres factores que han sido decisivos: i) la renovación del contrato y la subida del precio del alquiler (en el caso de Noemí, la subida fue de 800 a 1.600 euros); ii) 
las condiciones de habitabilidad y el poco confort de la vivienda; y iii) las prácticas de acoso a través de reformas en la escalera o el abandono en las tareas de mantenimiento de los edificios.

De todas las personas entrevistadas, seis dicen sentirse expulsadas del barrio. Es importante tener en cuenta las diferencias que se establecen entre los inquilinos que viven en una vivienda que pertenece a un pequeńo propietario, y aquellos que lo hacen en edificios que pertenecen a un mismo propietario (propiedad vertical). Una de las formas en que se favorece la salida de los inquilinos pasa por el cambio de propiedad de los edificios de manos de antiguos propietarios a nuevos actores, que pueden ser sus descendientes, o la venta a inmobiliarias y fondos de inversión. La muerte o el envejecimiento de la persona propietaria, con la que se tenía una relación más directa, lleva a que el edificio pase a sus descendientes, que en algunos casos ponen en venta el edificio. Los compradores del nuevo edificio acostumbran reformar las viviendas, destinándolas al alquiler temporal (turístico o estacional) o a nuevos residentes, pero con un fuerte incremento del precio. ${ }^{3}$

En las entrevistas han aparecido hasta tres estrategias de las inmobiliarias. Una de ellas es la no renovación del contrato de alquiler, que con la Ley de Arrendamientos Urbanos (LAU) 2013 era de tres años como máximo. Lina explica que todavía se está procediendo al vaciado de la finca donde vivía, ya que aún quedan dos vecinas con contrato vitalicio a las que no pueden echar. Sabe que se están haciendo obras en viviendas que han quedado vacías y sus antiguos vecinos, con los que todavía mantiene contacto, le cuentan que las obras y el ruido son "un infierno". Una segunda estrategia es la de indemnizar a los inquilinos con contratos de larga duración o indefinidos para poder poner la vivienda a la venta a "precios de mercado".

La finca pertenecía a una señora que se murió en el 2010 y la compró una empresa (...). A esta señora le pertenecía todo el edificio, se muere y los hijos lo venden a esta empresa... Yo creo que compró los cuatro portales, por lo menos compró el mío. Pero de esos cuatro portales, hay uno que es de pisos para turistas. En mi portal, esta empresa amablemente le pidió a la gente que se largara o les debió haber dado algo de dinero porque, claro, estaban con alquileres antiguos. (Rosa, 55 años, llegó al barrio en 2012)

La tercera estrategia tiene que ver con el acoso de los inquilinos (mobbing) a través de obras de reforma, el no mantenimiento del edificio, la generación de ruido constante o de desperfectos que afectan las condiciones de habitabilidad de la finca, o las ocupaciones de pisos. Sonia vivía en un edificio de propiedad vertical, con vecinos que tenían situaciones contractuales diferentes. A partir de 2016, coincidiendo con el boom del barrio, la propietaria de su edificio arregló diversas viviendas desocupadas y las incorporó al mercado a precios elevados. Vivió un proceso traumático de acoso y expulsión por parte de los vecinos: uno de los pisos "vacíos" se anunciaba

3 En el mercado inmobiliario de Barcelona funcionan de forma bastante extendida los denominados pases (flipping) entre diferentes empresas. Estas se especializan en una fase específica del proceso de reforma integral del edificio: unas localizan el edificio, otras desalojan a los vecinos, otras realizan el proceso de reforma de las viviendas y a continuación otras empresas las venden o las alquilan (uso residencial o turístico). En cada uno de estos pases el precio de la vivienda se incrementa. 
en Airbnb, algunas ocupaciones, una intervención de Desokupa, ${ }^{4}$ la ruptura de las puertas de entrada y de la azotea. En el momento de renovación de su contrato le subieron de 650 euros a 950 euros sin hacer ningún tipo de reforma en un apartamento viejo y que necesitaba adecuarse.

La actividad turística también ejerce un rol significativo para entender los procesos de expulsión en el barrio. Aunque Sant Antoni no tiene una presencia importante en las guías turísticas, porque no existe en él ningún monumento destacable, muchas entrevistas hacen continuas referencias a la apertura del mercado de Sant Antoni y al efecto que puede tener en la atracción de turistas. Son constantes las comparaciones con la Boquería (el mercado más famoso de la ciudad) y lo que podríamos definir como un proceso de "boquerización", es decir, la transformación de un mercado de alimentos que da servicio a la población que vive en el barrio/ ciudad, a uno que se especializa en dar servicios al turismo y que se convierte en un producto turístico. La transformación de los mercados municipales es frecuentemente causa y consecuencia de los procesos de gentrificación en otros puntos del planeta (González, 2018). Núria habla extensamente del turismo y la gentrificación relacionado con el mercado y la oferta comercial y de ocio:

Tengo miedo por la gentrificación que puede suponer, porque si tiene que ser una Boquería 2.0, me piro, me voy (...). He entrado una vez ahora que lo han inaugurado ${ }^{5}$ es como que yo estoy a la expectativa, que me gusta por un lado, porque los paradistas que son de toda la vida han mejorado sus condiciones laborales (...) es maravilloso, pero yo no quiero que eso se convierta en un pretexto para que suban precios, para que solo haya degustación, no sé, un mercado mercado. (Núria, 29 ańos, residente desde 2017)

Las personas entrevistadas perciben el impacto del turismo a través de dos procesos: la transformación del tejido comercial, especialmente en el ámbito de la restauración; y la aparición de apartamentos turísticos. El barrio, debido a su centralidad y su excelente red de transporte público, es objeto de numerosas conversiones de viviendas en apartamentos turísticos, lo que comporta un elemento más de presión sobre los precios y expulsión de los habitantes. En diciembre de 2016 se contabilizaban 904 ofertas de apartamentos o habitaciones turísticas en la página de Airbnb, o lo que es lo mismo, aproximadamente cinco anuncios por cada cien viviendas. Seis de las personas entrevistadas se han referido a problemas de convivencia originados por la presencia de apartamentos turísticos.

\section{Discusión y reflexiones finales}

Hemos estudiado el caso del barrio de Sant Antoni para profundizar en la relación entre el mercado de la vivienda, las estrategias e itinerarios residenciales de la población y la transformación sociodemográfica en el contexto actual de producción de

\footnotetext{
Desokupa es una empresa dedicada al desalojo de viviendas ocupadas.

5 El mercado municipal de Sant Antoni cerró en 2007 para su reforma integral y abrió en 2018. Está catalogado como patrimonio de la ciudad por su arquitectura de hierro característica del siglo xIx.
} 
espacio urbano neoliberal, así como para poner de relieve la importancia de nuevos elementos en los procesos de gentrificación, que podrían estar manifestándose también en otros barrios de las grandes urbes españolas y del sur de Europa. A partir de la recuperación de la última crisis económica, los procesos de gentrificación se han extendido a diversos barrios de la ciudad central, áreas que habían permanecido al margen de procesos anteriores y que han experimentado una fuerte revalorización, muy vinculada a la participación de las clases medias en los flujos residenciales hacia los espacios centrales. El uso de una metodología mixta nos ha permitido diseccionar, a través del uso de una fuente pionera de datos de flujos, los procesos de transformación sociodemográfica, así como profundizar en las experiencias de las personas que viven o han vivido en el barrio y recoger el testimonio sobre su transformación.

El papel de la vivienda es central para entender las estrategias residenciales de los vecinos del barrio. Así nos lo muestran los resultados del trabajo de campo. El fuerte incremento de los precios experimentado en el último lustro ha puesto en jaque la permanencia en el barrio, sobre todo para aquellas personas que han tenido que afrontar una renovación del contrato de alquiler o que cruzaban las edades de emancipación del hogar familiar. Aumenta el esfuerzo económico de las familias para hacer frente al coste de la vivienda y se acentúan y extienden los procesos de inseguridad residencial. El desplazamiento de parte de la población amenaza el fuerte sentido de comunidad e identidad del barrio, debilita la cohesión social y puede generar un deterioro de las condiciones de salud (Vásquez-Vera et al., 2019), un escenario que ha llevado a la articulación de prácticas de resistencia a nivel de barrio y ciudad. Las redes familiares y sociales pueden aparecer como única fórmula para flanquear un mercado de la vivienda tan selectivo, en el que no ha ayudado la conversión de parte del stock a uso turístico. El análisis cuantitativo nos ofrece más evidencia sobre esos relatos. Como dato relevante en la siempre complicada tarea de medición de los procesos de expulsión en barrios gentrificados (Easton et al., 2020), observamos que no estaría aumentando la frecuencia con la que la población cambia de vivienda, pero sí el destino de los cambios de residencia. En este sentido, disminuyen los movimientos de permanencia en el barrio y aumenta el peso de los movimientos hacia otros barrios con menos ingresos o a otros municipios de la metrópolis, sobre todo entre la población de niveles socioeconómicos más bajos. Se confirmaría así la contribución de este tipo de dinámicas locales en espacios gentrificados a una tendencia más general hacia la suburbanización de la pobreza que se ha observado en ciudades del norte de Europa (Bailey \& Minton, 2018; Hochstenbach \& Musterd, 2018).

En el otro lado de la moneda nos encontramos con un perfil de nuevos vecinos cada vez más selectivo a favor de la población de la franja de edad adulta más joven, con niveles educativos altos y nacida en el extranjero. Los testimonios de las personas entrevistadas subrayan como principales atractivos aspectos relacionados con la localización, pero especialmente con la calidad de vida urbana: provisión de infraestructuras de transporte (gentrificación por accesibilidad), acceso a todo tipo de servicios y equipamientos de cercanía y, paradójicamente, aspectos relacionados con el potente tejido asociativo que permea el barrio, así como su vida social y comunitaria. Como consecuencia de ambos procesos, el proceso de sustitución de 
la población es intenso, con un protagonismo cada vez más decidido de una población de mayor nivel socioeconómico que ha llegado de otros lugares del mundo y que muestra una fuerte transitoriedad. Sant Antoni sería, pues, un ejemplo de barrio en el que se superponen diferentes capas en la transformación sociodemográfica asociada al proceso de gentrificación: una más clásica, que nos hablaría de la sustitución poblacional de grupos de diferentes estratos socioeconómicos; y otra manifestación más contemporánea en la que una buena parte de la nueva población residente es internacional y se caracteriza por una presencia más efímera en el barrio. Este último rasgo abre la puerta a incluir entornos situados más allá de los centros históricos, que habían protagonizado hasta ahora los estudios de caso, como espacios en los que también se observan dinámicas propias de la gentrificación transnacional (Cocola-Gant \& López-Gay, 2020; Jover \& Díaz-Parra, 2019; Sigler \& Wachsmuth, 2015).

\section{Agradecimientos}

Agradecemos la colaboración de todas las personas y entidades entrevistadas, al Departamento de Estadística del Ayuntamiento de Barcelona por su apoyo continuo en el suministro de datos y a los revisores anónimos del manuscrito por sus buenas sugerencias. Parte de la investigación se ha realizado en el contexto del Programa Talent de la Universitat Autònoma de Barcelona y del Programa Cerca de la Generalitat de Catalunya. Antonio López-Gay también es investigador del Centre d'Estudis Demogràfics (CED/CERCA).

\section{Referencias bibliográficas}

Aalbers, M. (2019). Introduction to the Forum. From third to fifth-wave gentrification. Tijdschrift voor economische en sociale geografie, 110(1), 1-11. https://doi.org/10.1111/ tesg. 12332

Bailey, N. \& Minton, J. (2018). The suburbanisation of poverty in British cities, 2004-16: Extent, processes and nature. Urban Geography, 39(6), 892-915. https://doi.org/10.1 080/02723638.2017.1405689

Bayona, J. \& López-Gay, A. (2011). Concentración, segregación y movilidad residencial de los extranjeros en Barcelona. Documents d'anàlisi geogràfica, 57(3), 381-412. https://doi. org/10.5565/rev/dag. 234

Benach, N. \& Albet, A. (2018). La gentrificación como una estrategia global. Papers: Regió Metropolitana de Barcelona: Territori, estratègies, planejament, 60, 17-23. https://www. raco.cat/index.php/PapersIERMB/article/view/339237

Benson, M. \& O'Reilly, K. (2009). Migration and the search for a better way of life: A critical exploration of lifestyle migration. The Sociological Review, 57(4), 608-625. https://doi. org/10.1111/j.1467-954X.2009.01864.x 
Blázquez-Salom, M., Blanco-Romero, A., Gual-Carbonell, J. \& Murray, I. (2019). Tourist gentrification of retail shops in Palma (Majorca). En C. Milano, J. M. Cheer \& M. Novelli (Eds.), Overtourism: Excesses, discontents and measures in travel and tourism (pp. 39-69). CABI.

Caballero, L. (2018). Procesos de desplazamiento y desposesión en contextos urbanos. El caso de Sant Antoni (Barcelona). Periferia: revista de recerca $i$ formació en antropologia, 23(1), 31-55. https://doi.org/10.5565/rev/periferia.634

Cano, G. \& Etxezarreta, A. (2014). La crisis de los desahucios en Espańa: respuestas institucionales y ciudadanas. Revista de Economia Critica, 17, 44-57. http://www. revistaeconomiacritica.org/sites/default/files/revistas/n17/03_Cano-Etxezarreta_ Crisis-de-los-deshaucios.pdf

Cocola-Gant, A. (2016). Alojamiento turístico y desplazamiento de población. En ContestedCities International Conference, 1-15. http://contested-cities.net/working-papers/2016/ alojamiento-turistico-y-desplazamiento-de-poblacion/

Cocola-Gant, A. (2018). Tourism gentrification. En L. Lees \& M. Phillips (Eds.), Handbook of gentrification studies (pp. 281-293). Edward Elgar Publishing.

Cocola-Gant, A. \& López-Gay, A. (2020). Transnational gentrification, tourism and the formation of 'foreign only' enclaves in Barcelona. Urban Studies, 57(15), 3025-3043. https://doi.org/10.1177/0042098020916111

Easton, S., Lees, L., Hubbard, P. \& Tate, N. (2020). Measuring and mapping displacement: The problem of quantification in the battle against gentrification. Urban Studies, 57(2), 286-306. https://doi.org/10.1177/0042098019851953

García-López, M. À., Jofre-Monseny, J., Martínez Mazza, R. \& Segú, M. (2019). Do shortterm rental platforms affect housing markets? Evidence from Airbnb in Barcelona. IEB Working Paper, 2019(5). https://papers.ssrn.com/sol3/papers.cfm?abstract_ $\mathrm{id}=3428237$

Glass, R. (1964). Introduction: Aspects of change. En London: Aspects of change. Centre for Urban Studies, report n. ${ }^{\circ}$ 3. MacKibbon and Kee.

González, S. (2018). Contested markets, contested cities: Gentrification and urban justice in retail spaces. Routledge.

González-Leonardo, M., López-Gay, A. \& Recaño, J. (2019). Descapitalización educativa y segunda oleada de despoblación. Perspectives Demogràfiques, 16. https://doi. org/10.13140/RG.2.2.12099.22560

Gotham, K. F. (2005). Tourism gentrification: The case of New Orleans' Vieux Carre (French Quarter). Urban Studies, 42(7), 1099-1121. https://doi. org/10.1080/00420980500120881

Hochstenbach, C. \& Musterd, S. (2018). Gentrification and the suburbanization of poverty: Changing urban geographies through boom and bust periods. Urban Geography, 39(1), 26-53. https://doi.org/10.1080/02723638.2016.1276718

Janoschka, M., Sequera, J. \& Salinas, L. (2014). Gentrification in Spain and Latin America - a critical dialogue. International Journal of Urban and Regional Research, 38(4), 12341265. https://doi.org/10.1111/1468-2427.12030

Jover, J. \& Díaz-Parra, I. (2019). Gentrification, transnational gentrification and touristification in Seville, Spain. Urban Studies, 57(15), 3044-3059. https://doi. org/10.1177/0042098019857585 
Lees, L., Shin, H. B. \& López-Morales, E. (2016). Planetary gentrification. John Wiley \& Sons. López-Gay, A. (2018). Cambio en la composición social y gentrificación en Barcelona: una mirada a través de los flujos migratorios y residenciales. Papers: Regió Metropolitana de Barcelona: Territori, estratègies, planejament, 60, 80-93. https://www.raco.cat/index. php/PapersIERMB/article/view/339242

López-Gay, A. \& Andújar-Llosa, A. (2020). Gentrificación y cambios sociodemográficos en los barrios de Barcelona y Madrid: una mirada a través de los flujos migratorios y residenciales. En J. D. Sempere, C. Cortés Samper, E. Cutillas Orgilés \& J. R. Valero Escandell (Eds.), Población y territorio. España tras la crisis (pp. 313-333). Comares.

López-Gay, A., Sales, J., Solana, M., Fernández, A. \& Peralta, A. (2019). Midiendo los procesos de gentrificación en Barcelona y Madrid: una propuesta metodológica. En CTV 2019. Proceedings: XIII International Conference on Virtual City and Territory: "Challenges and paradigms of the contemporary city”. UPC, Barcelona, 2-4 octubre, 2019. Centre de Política de Sòl i Valoracions (Crsv) / Universitat Politècnica de Catalunya (UPC). http://dx.doi.org/10.5821/ctv. 8680

López-Rodríguez, D. \& de los Llanos Matea, M. (2019). Evolución reciente del mercado del alquiler de vivienda en España. Boletín Económico (sep). https://www.bde.es/f/webbde/ SES/Secciones/Publicaciones/InformesBoletinesRevistas/ArticulosAnaliticos/19/T3/ descargar/Fich/be1903-art25.pdf

Ministerio de Educación y Formación Profesional (MEFP). (2020). Sistema Estatal de Indicadores de la Educación 2020. Secretaría General Técnica, Madrid. https://sede.educacion.gob. es/publiventa/d/23979/19/00

Ministerio de Fomento. (2020). Valor tasado medio de vivienda libre, años 1995-2007. [Fichero de datos]. http://www.fomento.gob.es/BE2/sedal/35101000.XLS

Módenes, J.A. (2019). Elinsostenibleaumento dela inseguridad residencialen España. Perspectives demogràfiques, 13. https://ced.uab.cat/PD/PerspectivesDemografiques_013_ESP.pdf

Musterd, S., Bontje, M. \& Rouwendal, J. (2016). Skills and cities. Routledge.

Observatori Metropolità de l'Habitatge de Barcelona (о-HB). (2019). L'habitatge a la metrópoli de Barcelona, 2018. o-HB. https://www.ohb.cat/wp-content/uploads/2019/07/Habitat ge_metropolis_2018.pdf

Quaglieri, A. (2020). Poblaciones móviles y anclajes en la ciudad turística. Tesis Doctoral, Universitat Rovira i Virgili.

Sassen, S. (2011). Cities in a world economy. Pine Forge Press.

Sigler, T. \& Wachsmuth, D. (2015). Transnational gentrification: Globalisation and neighbourhood change in Panama's Casco Antiguo. Urban Studies, 53(4), 705-722. https://doi.org/10.1177/0042098014568070

Slee, T. (2017). What's yours is mine: Against the sharing economy. Or Books.

Smith, N. (1979). Toward a theory of gentrification a back to the city movement by capital, not people. Journal of the American planning association, 45(4), 538-548. https://doi. org/10.1080/01944367908977002

Sorando, D. \& Ardura, Á. (2018). Procesos y dinámicas de gentrificación en las ciudades espańolas. Papers: Regió Metropolitana de Barcelona: Territori, estratègies, planejament, 60, 34-47. https://www.raco.cat/index.php/PapersIERMB/article/view/339239 
Sorando, D. \& Leal, J. (2019). Distantes y desiguales: el declive de la mezcla social en Barcelona y Madrid. Reis: Revista española de investigaciones sociológicas, 167, 125-148. http:// dx.doi.org/10.5477/cis/reis.167.125

Thompson, B. Y. (2018). Digital nomads: Employment in the online gig economy. Glocalism: Journal of Culture, Politics and Innovation, 1. https://glocalismjournal.org/digitalnomads-employment-in-the-online-gig-economy-2

Vásquez-Vera, H., Fernández, A., Novoa, A. M., Delgado, L., Barcala, J., Macías, C. \& Borrell, C. (2019). Our lives in boxes: perceived community mediators between housing insecurity and health using а Рнотоуогсе approach. International Journal for Equity in Health, 18(1), 52. https://doi.org/10.1186/s12939-019-0943-0

Vives-Miró, S., González-Pérez, J. M. \& Rullan, O. (2015). Home dispossession: the uneven geography of evictions in Palma (Majorca). DIE ERDE - Journal of the Geographical Society of Berlin, 146(2-3), 113-126. https://doi.org/10.12854/erde-146-10

Wachsmuth, D. \& Weisler, A. (2018). Airbnb and the rent gap: Gentrification through the sharing economy. Environment and Planning A: Economy and Space, 50(6), 11471170. https://doi.org/10.1177/0308518X18778038

White, P. \& Hurdley, L. (2003). International migration and the housing market: Japanese corporate movers in London. Urban Studies, 40(4), 687-706. https://doi. org/10.1080/0042098032000065254 